\title{
Obesity and the risk of late mortality after aortic valve replacement with small prosthesis
}

\author{
Biao Wang, Hongyang Yang, Shuming Wu, Guangqing Cao and Hongling Yang*
}

\begin{abstract}
Background: Whether obesity is related to late mortality with implantation of small aortic prosthesis remains to be clarified. This study was aimed to evaluate the effect of obesity on late survival of patients after aortic valve replacement (AVR) with implantation of small aortic prosthesis (size $\leq 21 \mathrm{~mm}$ ).

Methods: From January 1998 to December 2008, 307 patients in our institution who underwent primary AVR with smaller prostheses survived the 30 days after surgery. Patients were defined as normal if body mass index (BMI) was $<24 \mathrm{~kg} / \mathrm{m}^{2}$, as overweight if BMl $24-27.9 \mathrm{~kg} / \mathrm{m}^{2}$, and as obese if BMI $\geq 28 \mathrm{~kg} / \mathrm{m}^{2}$. Data of New York Heart Association (NYHA) functional classification, left ventricular ejection fraction (LVEF), effective orifice area index (EOAl), and left ventricular mass index (LVMI) of the patients collected at the 3rd month (M), 6th M, 1st year (Y), 3rd $Y$, 5th $Y$, 8th $Y$ after operation respectively.

Results: By multivariable analysis, obesity was an independent factor of late mortality (hazard ratio [HR]: 1.62; $P=0.01)$. The obesity and overweight group had more poor survival $(p<0.001)$ and higher proportion of NYHA class III/IV $(p<0.01)$ compared with the normal group. Lower EOAI and higher LVMI were found in obesity and overweight group, but we saw no significant difference about LVEF among the three groups.

Conclusions: Obesity was associated with increased late mortality of patients after AVR with implantation of small aortic prosthesis. Being obese or and overweight may also affect the NYHA classification, even in the longer term. EOAl should be improved where possible, as it may reduce late mortality and improve quality of life in obese or overweight patients.
\end{abstract}

Keywords: Aortic valve replacement, Small aortic root, Obesity, Body mass index

\section{Background}

The aortic annulus of Chinese individuals is typically smaller than that of people of European descent, and thus our hospital in china treats many patients who have a small aortic annulus in aortic valve replacement (AVR). Techniques developed to expand the annulus [1-3] were rarely applied in clinical circumstances because these techniques may increase the complexity and risk in an operation $[4,5]$; most surgeons prefer to use a small aortic prosthesis instead of expanding the annulus. Yet the use of a small aortic prosthesis may be associated with obstruction of left ventricular output, resulting in a higher transvalvular gradient and patient-prosthesis mismatch (PPM) [6]. Studies $[7,8]$ have demonstrated

\footnotetext{
* Correspondence: yanzy055@yeah.net

Department of Cardiovascular Surgery Qilu Hospital, Shandong University, Jinan, China
}

that mortality was higher in patients receiving a small aortic prosthesis; Further complicating the issue, there was a rapid increase in the obese population in recent decades, and obesity has become an important factor that seriously affects the health of Chinese people [9]. However, it is unclear whether obesity is related to later mortality in AVR. Here we report 307 patients from a single center in China who underwent AVR with small prostheses (size $\leq 21 \mathrm{~mm}$ ); our long-term follow-up study investigated if obesity was an independent predictor of long-term mortality for these patients after AVR.

\section{Methods \\ Patients}

From January 1998 through December 2008, a total of 328 patients underwent primary AVR (size $\leq 21 \mathrm{~mm})$ at the Department of cardiovascular surgery of Qilu Hospital, 
Shandong University, Jinan, China. 21 (6.4\%) of the 328 patients who died within 30 days following surgery were excluded, so the study population was composed of 307 patients (mean age $56 \pm 12.6), 58.3 \%(n=179)$ are females. Etiology was rheumatic disease in $44.3 \%(\mathrm{n}=136)$ patients, congenital bicuspid valve in $25.5 \%(\mathrm{n}=78)$ patients, degenerative calcific disease in $22.4 \%(\mathrm{n}=69)$ patients, and endocarditis in $7.8 \%(\mathrm{n}=24)$ patients. $40.7 \%(\mathrm{n}=125)$ received bioprosthesis. Preoperative coronary angiography was performed in all patients aged $\geq 50$ years old and in all patients with angina or in whom coronary artery disease was suspected on a clinical basis. $17.5 \%(\mathrm{n}=54)$ underwent concomitant coronary artery bypass graft surgery (CABG). The study was approved by the ethics review committee for human studies at the School of Medicine, Shandong University.

\section{Data collection}

Pre-operative and operative data were prospectively collected and validated (Table 1). Follow-up information was available in all 307 patients. Most $(68.4 \%, \mathrm{n}=210)$ were followed up regularly at our institution; telephone, E-mail, post, or out-patient interviews $(29 \%, n=89)$ were conducted with patients or first-degree relatives, to confirm mortality and get related data including weight, height, symptom, capacity for action and results of Twodimensional and Dopper echocardiography; mortalities among the remaining patients $(1.8 \%, \mathrm{n}=8)$ were determined using national death and survival data registry.

\section{BMI definition}

We adopted the most commonly used BMI classification system for adults in China [10]. Patients were classified as normal weight if BMI was $<24 \mathrm{~kg} / \mathrm{m}^{2}$, as overweight if BMI $24-27.9 \mathrm{~kg} / \mathrm{m}^{2}$, and as obese if $\mathrm{BMI} \geq 28 \mathrm{~kg} / \mathrm{m}^{2}$. The cohort was divided into 3 groups according to BMI: normal weight $(\mathrm{n}=185,60.2 \%)$, overweight $(\mathrm{n}=94$, $30.6 \%)$, and obese $(n=28,9.2 \%)$.

\section{Statistical methods}

Pre-operative and operative data are expressed as mean \pm SD or percentages. Repeated analysis of variance (ANOVA) measures were used to test the significance of changes in data in different groups of the study; the Sheffe post-hoc test was utilized for multiple comparisons. The chi-square analysis or Fisher exact test was

Table 1 Baseline pre-operative and operative data of total study groups in patients who survive the first postoperative month after AVR

\begin{tabular}{|c|c|c|c|}
\hline & $\begin{array}{l}\mathrm{BMI}<24 \\
\mathrm{n}=185\end{array}$ & $\begin{array}{l}24 \leq \mathrm{BMI} \leq 27.9 \\
\mathrm{n}=94\end{array}$ & $\begin{array}{l}\mathrm{BMI} \geq \mathbf{2 8} \\
\mathrm{n}=\mathbf{2 8}\end{array}$ \\
\hline Age, y & $56 \pm 11.5$ & $54 \pm 14.7$ & $57.8 \pm 10.3$ \\
\hline Sex (female),n (\%) & $116(64.4)$ & $44(47.3)^{*}$ & $19(67.8) \dagger$ \\
\hline Body surface area, $\mathrm{m}^{2}$ & $1.72 \pm 0.32$ & $1.78 \pm 0.21^{*}$ & $1.86 \pm 0.28^{*}+$ \\
\hline \multicolumn{4}{|l|}{ NYHA functional class, n (\%) } \\
\hline III & $85(45.9)$ & $36(38.3)$ & $13(46.4)$ \\
\hline IV & $66(35.7)$ & $28(29.8)$ & $8(28.6)$ \\
\hline LVEF, \% & $49.6 \pm 9.2$ & $52.7 \pm 7.8$ & $51.8 \pm 8.1$ \\
\hline \multicolumn{4}{|l|}{ Pathology, n (\%) } \\
\hline Stenosis & $64(34.6)$ & $26(27.6)$ & $8(28.6)$ \\
\hline Insufficiency & $20(10.8)$ & $12(12.8)$ & $6(21.4)^{*} \dagger$ \\
\hline Mixed & $101(54.6)$ & $56(59.6)$ & $14(50)$ \\
\hline Diabetes mellitus, n (\%) & $26(14.1)$ & $20(21.2)^{*}$ & $8(28.6)^{*} \dagger$ \\
\hline Systemic hypertension, n (\%) & $41(22.1)$ & $28(29.8)^{*}$ & $13(46.4)^{*} \dagger$ \\
\hline Chronic lung disease, n (\%) & $21(11.4)$ & $15(15.9)^{*}$ & $6(21.4)^{*}+$ \\
\hline$A F, n(\%)$ & $75(40.5)$ & $28(29.8)^{*}$ & $9(32.7)^{*}$ \\
\hline \multicolumn{4}{|l|}{ Operative data } \\
\hline Concomitant CABG & $30(16.2)$ & $18(19.1)^{*}$ & $6(21.4)^{*}+$ \\
\hline $\mathrm{EOAl}, \mathrm{cm}^{2} / \mathrm{m}^{2}$ & $1.07 \pm 0.12$ & $0.96 \pm 0.08^{*}$ & $0.81 \pm 0.05^{*}+$ \\
\hline CPB time, min & $100 \pm 31$ & $104 \pm 42$ & $112 \pm 28^{*} \dagger$ \\
\hline Mechanical prosthesis, \% & $126(68.5)$ & $54(57.4)$ & $16(57.1)$ \\
\hline
\end{tabular}

*significant difference from normal $(\mathrm{BMI}<24)$ group; + significant difference from overweight $(24 \leq \mathrm{BMI} \leq 27.9) \mathrm{group}$.

Abbreviations: AVR Aortic valve replacement, BMI Basic mass index, NS Not significant, NYHA New York Heart Association, LVEF Left ventricular eject fraction,

$A F$ Atrial fibrillation, $C A B G$ Coronary artery bypass graft, EOAl Effective orifice area index, CPB Cardiopulmonary bypass. 
used to compare categorical data. Cumulative probability of survival was analyzed by constructing Kaplan-Meier curves among patients in three groups, and inter-group comparisons were performed using the long-rank test. Cox proportional-hazards regression models were used to determine whether overweight and obesity were associated with survival after AVR. The related variables were entered into the Cox analyses of observed survival. Significant $(\mathrm{P} \leq 0.1)$ variables on univariate analysis were reentered in a multivariable model examining predictors of survival. A propensity score was calculated using a logistic regression analysis that identified variables, that may be associated with BMI. Variables included in the logistic regression analysis were: sex, age, body surface area (BSA), diabetes mellitus, systemic hypertension, chronic lung disease, EOAI, and cardiac pulmonary bypass $(\mathrm{CPB})$ time. The propensity score was then incorporated into subsequent proportional-hazards models. Results were expressed as the hazard ratio (HR) and 95\% of confidence interval (CI). All statistical analyses were carried out using SPSS 17.0 (SPSS, Chicago, IL).

\section{Results}

In this study, normal BMI $\left(<24 \mathrm{~kg} / \mathrm{m}^{2}\right)$ was present in $62.5 \%$ of the patients $(\mathrm{n}=185)$, overweight BMI $\left(24-27.9 \mathrm{~kg} / \mathrm{m}^{2}\right)$ presented in $30.6 \%(\mathrm{n}=94)$ and obesity BMI $\left(\geq 28 \mathrm{~kg} / \mathrm{m}^{2}\right)$ in $9.2 \%(\mathrm{n}=28)$. Pre-operative and operative data are shown in Table 1. Compared with the normal group, those patients in overweight and obesity groups had a smaller EOAI, a larger BSA, lower prevalence of $\mathrm{AF}$, and a higher prevalence of diabetes mellitus, systemic hypertension, chronic lung disease, as well as concomitant coronary artery bypass grafting (CABG). The obesity group displayed a higher proportion of female patients than the overweight group, and predominant insufficiency was more frequent and CBP time longer in obesity group than the other two groups. We found no significant difference in the variables of age, NHYA class and prosthesis type (biological or mechanical) among three groups.

\section{Impact of BMI on morality}

Mean overall follow-up duration was $4.7 \pm 2.8$ years (median, 4.1 years; range: $0.2-10$ years). 68 deaths were observed during follow-up. The overall survival rate was $81.5 \% \pm 2.6 \%$ at 5 years and $54.3 \% \pm 1.4 \%$ at 10 years (Figure 1A). For obese patients, 5 -year survival $(65.1 \% \pm$ $1.8 \%)$ and 10 -year survival $(31.6 \% \pm 1.4 \%)$ were significantly lower than those of patients with normal BMI (5-year survival: $85.2 \% \pm 3.6 \%$; 10 -year survival: $65 \% \pm$ $2.2 \%$; $\mathrm{P}=0.007$; Figure $1 \mathrm{~B}$ ). The obese group also had significantly lower survival than the overweight group (5-years survival: $74.8 \% \pm 3.1 \%$; 10 -years survival: $52.2 \% \pm$ $2.0 \% ; \mathrm{P}=0.01$ ). Difference in survival between the

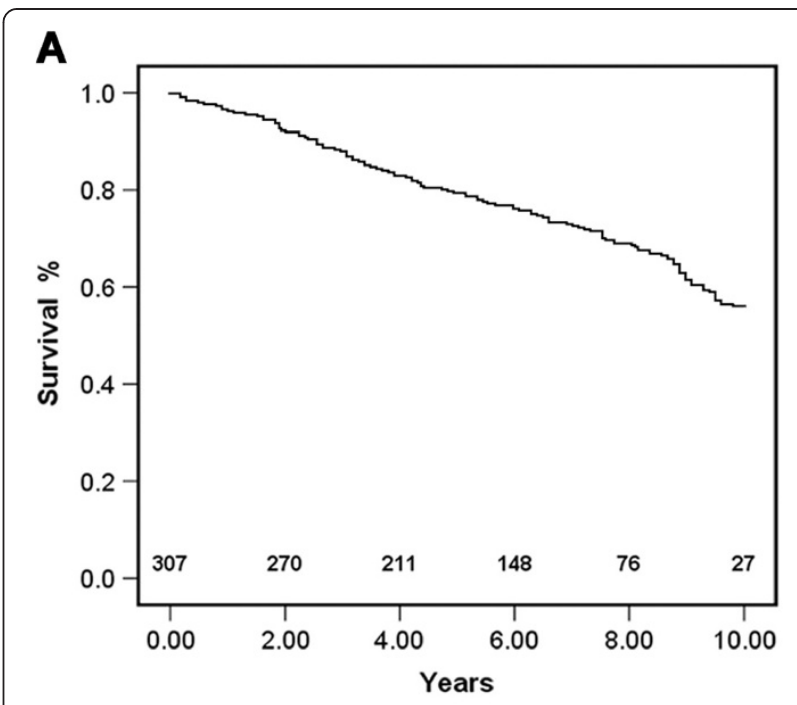

B

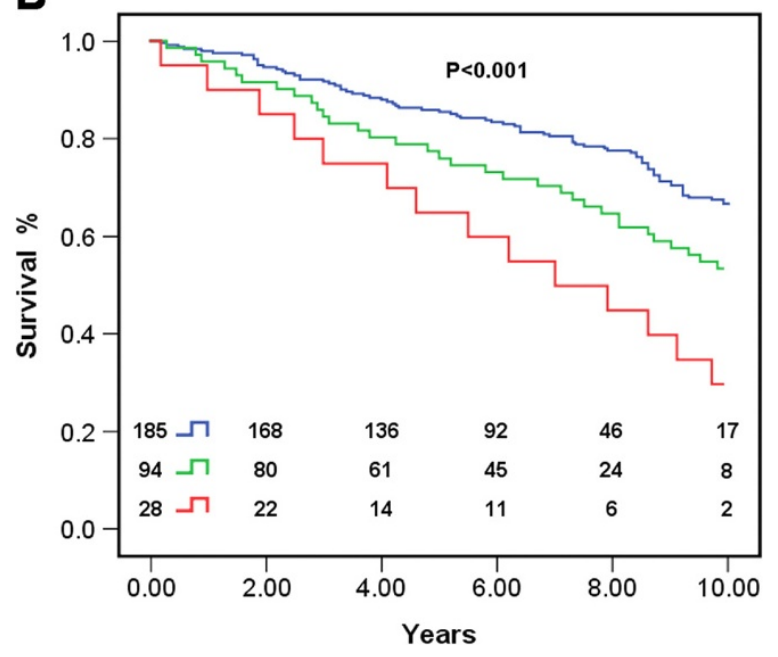

Figure 1 Overall survival and separate survival of three groups divided by body mass group (BMI). Blue indicates normal group (BMl $<24 \mathrm{~kg} / \mathrm{m}^{2}$ ); green indicates overweight group (BMI $\left.24-27.9 \mathrm{~kg} / \mathrm{m}^{2}\right)$; red line indicates obesity group $\left(\mathrm{BMl} \geq 28 \mathrm{~kg} / \mathrm{m}^{2}\right)$. A Overall survival \%. B Separate suvival \%.

normal and overweight groups was also statistically significant $(P=0.03)$, with the overweight group having a lower survival rate.

\section{Predictors of mortality}

According to univariate analysis (Table 2), the predictors of late post-operative mortality were old age, poor cardiac function, reduced LV ejection fraction (LVEF), suffering from diabetes, hypertension, chronic lung disease and atrial fibrillation (AF), concomitant CABG, use of a mechanical prosthesis, EOAI $\left(\leq 0.85 \mathrm{~cm}^{2} / \mathrm{m}^{2}\right)$, and obesity, with obesity presenting a higher level of statistical significance (HR: 1.84; 95\% CI: 1.46 to 2.26 ; P $<0.001$ ). Overweight also tended to be associated with higher 
Table 2 Results of univariate and multivariate analyses based on observed late (deaths within $\mathbf{3 0}$ days of aortic valve replacement excluded) survival using the cox regression

\begin{tabular}{|c|c|c|c|c|}
\hline & \multicolumn{2}{|c|}{ Univariate analysis } & \multicolumn{2}{|c|}{ Multivariate analysis 2} \\
\hline & p Value & HR $(95 \% \mathrm{Cl})$ & p Value & HR $(95 \% \mathrm{Cl})$ \\
\hline Age & $p<0.001$ & $1.34(1.12-1.58)$ & $p<0.001$ & $1.21(1.04-1.10)$ \\
\hline Sex & 0.08 & $0.92(0.72-1.14)$ & 0.21 & $0.89(0.84-0.95)$ \\
\hline Body surface area & NS & $1.34(1.14-1.53)$ & 0.75 & $1.29(1.10-1.50)$ \\
\hline NYHA functional calss III/IV & $p<0.001$ & $1.25(1.04-1.47)$ & 0.48 & $1.22(1.01-1.43)$ \\
\hline LVEF & $p<0.001$ & $1.58(1.12-2.06)$ & $p<0.001$ & $1.28(1.09-1.51)$ \\
\hline Predominant AS & 0.05 & $1.11(0.84-1.40)$ & 0.43 & $1.04(0.86-1.24)$ \\
\hline Diabetes mellitus & $p<0.001$ & $1.21(1.02-1.12)$ & 0.01 & $1.02(0.75-1.32)$ \\
\hline Systemic hypertension & $p<0.001$ & 1.43(0.14-1.78) & $p<0.001$ & $1.20(0.87-1.53)$ \\
\hline Chronic lung disease & $p<0.001$ & $1.39(1.20-1.63)$ & 0.003 & $1.30(1.03-1.60)$ \\
\hline $\mathrm{AF}$ & $p<0.001$ & $1.27(1.04-1.56)$ & 0.12 & 1.16(0.89-1.48) \\
\hline \multicolumn{5}{|l|}{ Operative data } \\
\hline Concomitant CABG & 0.004 & $1.10(0.96-1.26)$ & 0.11 & $1.02(0.90-1.15)$ \\
\hline $\mathrm{EOAI} \leq 0.85 \mathrm{~cm}^{2} / \mathrm{m}^{2}$ & $p<0.001$ & $1.42(1.12-1.73)$ & 0.005 & $1.26(1.09-1.44)$ \\
\hline Mechanical prosthesis & 0.03 & $1.17(0.94-1.42)$ & 0.08 & $0.88(0.65-1.10)$ \\
\hline $24 \leq \mathrm{BMI} \leq 27.9$ & 0.01 & $0.92(0.71-1.15)$ & 0.34 & $0.68(0.50-0.92)$ \\
\hline $\mathrm{BMI} \geq 28$ & $p<0.001$ & $1.84(1.46-2.26)$ & 0.01 & $1.62(1.33-1.93)$ \\
\hline Propensity score & 0.75 & $1.51(1.18-1.94)$ & 0.53 & $1.73(1.34-2.12)$ \\
\hline
\end{tabular}

Bold indicates statistical significance on multivariate analysis. Analysis 1: without adjustment for propensity score. Analysis 2: with adjustment for propensity score. $\mathrm{Cl}$, Confidence interval; HR, Hazard ratio; AS, Aortic stenosis; BMI, Body mass index; other abbreviations as in Table 1.

mortality by univariate analysis (HR: 0.92; 95\% CI: 0.71 to $1.15 ; \mathrm{P}=0.01$ ). For multivariate analysis (Table 2), after adjustment of the variables with a $\mathrm{p} \leq 0.1$ on univariate analysis, the following variables were rendered not independently associated with long-term survival: poor cardiac function, concomitant CABG, and use of a mechanical prosthesis; overweight also failed to be an independent predictor (HR: 0.64 ; $95 \% \mathrm{CI}$ : 0.50 to 0.81 ; $\mathrm{P}=0.45)$, but obesity remained significantly associated with increased mortality (HR: 1.60 ; $95 \% \mathrm{CI}: 0.32$ to 1.91 ; $\mathrm{P}=0.008)$. After further adjustment for propensity score, the following variables were still independent predictors: old age (HR: 0.21; 95\% CI: 1.04 to $1.10 ; \mathrm{P}<0.001$ ), reduced LVEF (HR: 1.28; 95\% CI: 1.09 to $1.51 ; \mathrm{P}<0.001$ ), suffering from diabetes (HR: 1.02; 95\% CI: 0.75 to 1.32 ; $\mathrm{P}=0.01$, hypertension (HR: 1.01 ; $95 \% \mathrm{CI}: 0.79$ to 1.33 ; $\mathrm{P}<0.001$ ), chronic lung disease (HR: 1.30 ; $95 \% \mathrm{CI}: 1.03$ to $1.60 ; \mathrm{P}=$ 0.003), EOAI (HR: 1.26 ; $95 \% \mathrm{CI}: 1.09$ to $1.44 ; \mathrm{P}=0.005$ ) and obesity (HR: 1.62; 95\% CI: 1.33 to 1.93 ; $\mathrm{P}=0.01$ ).

\section{Discussion}

Here we reported the long-term follow-up with patients who underwent aortic prosthesis replacement with smaller prosthesis (size $\leq 21 \mathrm{~mm}$ ) in china. A notable finding was produced that obesity $\left(B M I \geq 28 \mathrm{~kg} / \mathrm{m}^{2}\right)$ was an independent predictor of late mortality in patients undergoing AVR with small prosthesis. Obesity group and overweight group had poor survival and higher proportion of NYHA Function III/IV compared to normal group.

\section{Review of previous studies}

There have been some different opinions in the published reports about the impact of BMI on outcomes after AVR, but specialized research on AVR with small prosthesis was scarce. Several studies demonstrated that BMI is an independent predictor of mortality and clinic events after AVR. Parwis [11] revealed obesity as an independent predictor of hospital and longer mortality in patients who underwent valve surgery. William [12] studied patients having AVR for AS with or without concomitant coronary artery bypass grafting and revealed a better survival in patients with low BMI compared to patients with higher BMI. On the other hand, others failed to found a significant effect of BMI on postoperative outcomes. Vinod [13] reported patients with BMI 24 or less are at significantly increased risk of inhospital and long-term mortality after cardiac valvular surgery. This high-risk patient population warrants careful risk stratification and options for less-invasive valve therapies. Robert [14] found Increasing BMI has no independent association with worsened outcomes in the short or long term, and overweight patients have a survival benefit after surgery. So the relationship of BMI 
and long-term survival after AVR was controversial. The long-term survival research about BMI in small aortic root is rarely reported.

\section{Impact of BMI on long-term mortality and NYHA classification}

It is important to note that there may be some differences in AVR between China and Western countries; it is unknown whether this could affect the results of the research. For example, rheumatic disease accounted for the major etiology in this cohort although occurrence of degeneration was on the rise; mechanical valves were mostly used; and patients were younger and had less concomitant CABG.

In this study, we determined that obesity raised the long-term mortality, implying that higher BMI means higher risk of adverse outcomes for patients with small aortic prosthesis replacement. These results are consistent with some previous studies [11,12]. In addition, a higher proportion of patients with poor cardiac function were observed in the obesity group at one year after surgery, and that distinction increased over time. These findings suggest that high BMI is a possible indicator of poor long-term quality of life for patients with small aortic roots. Numerous earlier studies $[15,16]$ concluded that NYHA class of the patients could be ameliorated within a short period after operation. Nevertheless those studies they failed to keep up with its change in subsequent years after AVR.

\section{The long-term outcome of EOAI, LVEF, LVMI}

Several factors such as EOAI, LVEF and LVMI may directly contribute to a higher class of NHYA class $[17,18]$ in obesity and overweight group. We expelled LVEF from the list due to its insignificant change along with BMI increase. In contrast, EOAI and LVMI turned out to be related with BMI in our investigation. As a result, EOAI may associate with cardiac function and influence postoperative life quality. We also found EOAI to be also an independent predictor of late mortality in this research, which was in accordance with previous researches [17-20]. EOAI $\leq 0.85 \mathrm{~cm}^{2} / \mathrm{m}^{2}$ (considered as PPM) [21] could lead to increased late mortality after AVR, and that's why PPM should be avoided in patients with small aortic roots. It's a challenge for surgeons to select the optimal type and size of prosthesis, so that proper EOAI could be maintained in obese patients. Although suprannular stentless valves have been applied in clinic recent years to increase EOAI and prevent PPM, there have been some discrepancies in the results [22-27]. Annulus enlarging techniques, including Nicks procedure [1], the Manouguian technique [2] and the Konno procedure [3], allow for the implantation of prosthetic valves 1 or 2 size larger than the original size of the aortic annulus [28], and many studies have been frequently reported with good results, but some authors have reported increased operative mortality [28], so there is still no agreement about annulus enlarging techniques.

\section{Clinical implications}

Why does obesity affect the late mortality and NYHA functional class in patients with implantation of small aortic prosthesis? We attempted to throw light upon the question in the following aspects: obesity-related diseases, operation techniques and postoperative lifestyle. Being overweight or obese were associated with increased risk of underlying disease such as diabetes [29], hypertension [30], coronary artery disease [31,32] and other chronic diseases [33-35], which may increase the mortality in the long-term. We indicated in this research that diabetes, systemic hypertension and chronic lung disease were independent predictors of late morality in patients undergoing AVR with small prosthesis. So obesity-related disease should be taken into consideration in advance to evaluate risk of surgery and predict long-term outcomes for the patients.

According to the results in our study, we should reconsider the role of annulus-enlarging techniques even though they are often accompanied by increased morbidity and mortality after AVR. Such techniques may be meaningful to recommend as the best choice for the patients with obesity and relatively small aortic annulus requiring AVR, but implantation with small prosthesis, especially in younger patients [36], can effectively increase the EOAI and improve the long-term outcome and life quality. So in the future we should work to perfect annulus-enlarging techniques, including reducing the cross-clamp time and the occurrence of complication.

It should be noted that in normal-weight group the EOAI and LVMI also worsened three years later in spite of lower later mortality. The main reason may be an increase in BSA. In this study, we were informed that many people gained weight after AVR due to being less active and an improper diet. Since height changed little after operation, accumulation of weight may bring about larger BSA. It is important to instruct patients with small prosthesis to keep fit and control weight, which could certainly benefit their health after AVR.

\section{Conclusions}

This study analyzed the effects of BMI on the late mortality in patients undergoing AVR with small prosthesis. Results suggested that obesity was associated with increased late mortality after AVR in patients with implantation of small aortic prosthesis $($ size $\leq 21)$. Obesity and 
being overweight may also affect the NYHA function in the long term. EOAI should be improved where possible as it may reduce late mortality and improve life quality in such patients.

\section{Abbreviations}

AVR: Aortic valve replacement; BMI: Body mass index; NYHA: New York Heart Association; LVEF: Left ventricular ejection fraction; EOAl: Effective orifice area index; LVMI: Left ventricular mass index; PPM: Patient-prosthesis mismatch; AF: Atrial fibrillation; CABG: Coronary artery bypass graft; CPB: Cardiopulmonary bypass.

\section{Competing interests}

The authors declare that they have no competing interests.

\section{Authors' contributions}

This study was designed by BW and SW. BW and HY drafted the manuscript. All authors participated in the Data collection and compilation. GC and HY performed the statistical analysis. All authors read and approved the final manuscript.

Received: 11 November 2012 Accepted: 25 June 2013

Published: 15 July 2013

\section{References}

1. Nicks R, Cartmill T, Bernstein L: Hypoplasia of the aortic root. The problem of aortic valve replacement. Thorax 1970, 25:339-346.

2. Manouguian S, Seybold-Epting W: Patch enlargement of the aortic valve ring by extending the aortic incisions into the anterior mitral leaflet. New operative technique. J Thorac Cardiovasc Surg 1979, 78:402-412.

3. Konno S, Imai Y, lida Y, Nakajima M, Tatsuno K: A new method for prosthetic valve replacement in congenital aortic stenosis associated with hypoplasia of the aortic valve ring. J Thorac Cardiovasc Surg 1975, 70:909-917.

4. Shibata KE, Abe T, Sekine S, Chanda J: Suprannular aortic root enlargement in patients with small aortic annulus: efficacy and safety. Ann Thorac Cardiovasc Surg 1998, 4:262-265.

5. Sommers KE, David TE: Aortic valve replacement with patch enlargement of the aortic annulus. Ann Thorac Surg 1997, 63:1608-1612.

6. Walther T, Falk V, Langebartels G: Regression of left ventricular hypertrophy after stentless versus conventiaonal aortic valve replacement. Semin Thorac Cardiovasc Surg 1999, 11:18-21

7. Rao V, Christakis GT, Weisel RD: Changing pattern of valve surgery. Circulation 1996, 94:113-120.

8. Abdelnoor M, Hall KV, Nitter-Hauge S, Linderberg H, Ovrum E: Prognostic factors in aortic valve replacement associated with narrow aortic roots. Scand J Thorac Cardiovasc Surg 1986, 20:227-232.

9. Wang Y, Mi J, Shan XY, Wang QJ, Ge KY: Is China facing an obesity epidemic and the consequences? The trends in obesity and chronic disease in China. Int J Obes 2007, 31:177-188.

10. Zhou BF: Cooperative meta-analysis group of the working group on obesity in China predictive values of body mass index and waist circumference for risk factors of certain related diseases in chinese adults-study on optimal cut-off points of body mass index and waist circumference in vhinese adults. Biomed Environ Sci 2002, 15:83-96.

11. Parwis BR, David HA, Javier GC, Joanna C, Carol A, Bodian D: Impact of Body Mass Index on Early Outcome and Late Survival in Patients Undergoing Coronary Artery Bypass Grafting or Valve Surgery or Both. Am J Cardiol 2007, 100:1702-1708.

12. William CR, Carey CR, Travis JV: Effect of body mass index on survival in patients having aortic valve replacement for aortic stenosis with or without concomitant coronary artery bypass grafting. Am J Cardiol 2011, 108:1767-1771.

13. Vinod HT, W Brent K, Patrick DK, John DP, Omar ML, Edward PC: The impact of body mass index on morbidity and short- and long-term mortality in cardiac valvular surgery. J Thorac Cardiovasc Surg 2011, 142:1052-1061.

14. Robert L, Smith II, Morley AH: Does Body Mass Index Affect Outcomes for Aortic Valve Replacement Surgery for Aortic Stenosis. Ann Thorac Cardiovasc Surg 2012, 93:742-747.
15. Per K, Reinhold B, Lars-Gunnar H: Observed and relative survival after aortic valve replacement. J Am Coll Cardiol 2000, 35:747-756.

16. Jeremy JP, Michael SL, Mohammad B, Imran F, Eugene HB, William JS: Survival after aortic valve replacement for severe aortic stenosis with low transvalvular gradient and severe left ventricular dysfunction. J Am Coll Cardiol 2002, 39:1356-1363.

17. Mohty D, Malouf JF, Girard SE: Impact of prosthesis-patient mismatch on long-term survival in patients with small St. Jude medical mechanical prostheses in the aortic position. Circulation 2006, 113:420-426.

18. Dania M, Jean GD, Najmeddine E: Impact of mpact of prosthesis-patient mismatch on long-term survival after aortic valve replacement. J Am Coll Cardiol 2009, 53:39-47.

19. Tasca G, Mhagna Z, Perotti S: Impact of prosthesis-patient mismatch on cardiac events and midterm mortality after aortic valve replacement in patients with pure aortic stenosis. Circulation 2006, 113:570-576.

20. Moon MR, Pasque MK, Munfakh NA: Prosthesis-patient mismatich after aortic valve replacement: impact of age and body size on late survival. Ann Thorac Surg 2006, 81:481-488.

21. Dumesnil JG, Honos GN, Lemieux M, Beauchemin J: Validation and applications of indexed aortic prosthetic valve areas calculated by Doppler echocardiography. J Am Coll Cardiol 1990, 16:637-643.

22. Florian B, Walter BE, Sabine B, Ralf G, Inam W, Robert B: Hemodynamic comparison of bioprostheses for complete supra-annular position in patients with small aortic annulus. J Am Coll Cardiol 2005, 45:2054-2060.

23. Ina MW, Walter BE, Sabine B: Influence of completely supra-annular placement of bioprosthesisi on exercise hemodynamics in patients with a small aortic annulus. J Thorac Cardiovasc Surg 2007, 133:1234-1241.

24. Sandro G, Giorgio M, Romeo F, Paolo DC, Rocco C, Ugohho L: Usefulness of the cryolife O'Brien stentless suprannular aortic valve to prevent prosthesis-patient mismatich in the small aortic root. J Am Coll Cardiol 2002, 39:1845-1851.

25. A Marc G, Eugene HB, Joan MA: The carbomedics Top hat supraannular aortic valve: a multicenter study. Ann Thorac Surg 2003, 75:1175-1180.

26. Hany E: Predicting complication of top hat prosthesis in aortic valve replacement: suspicion can save lives. Ann Thorac Surg 2009, 87:676-677.

27. Suzanne R, Marin C, Jan N: Mechanical aortic valve prosthesis in the small aortic root: top-hat versus standard Carbomedics aortic valve. Ann Thorac Surg 2008, 86:64-70.

28. Molina JE: Enlargement of aortic annulus using a double-patch technique: a safe and effective method. Ann Thorac Surg 2002, 73:667-670.

29. David H: Obesity and diabetes: the links and common approaches. Prim Care Diabetes 2010, 4:105-112.

30. Chuang SY, Chou P, Hsu PF: Presence and progression of abdominal obesity are predictor of future high blood pressure and hypertension. Am J Hypertens 2006, 19:788-795.

31. Ninh TN, Xuan-M TN, James BW, Johnathan AS, John SL: Association of obesity with risk of coronary heart disease: findings from the National health and nutrition examination survey, 1999-2006. Surg Obes Relat Dis 2010, 6:465-469.

32. Auer J, Weber T, Berent R: Obesity, body fat and coronary atherosclerosis. Int J Cardiol 2005, 98:227-235.

33. Eleonora DG, Tiffany G, Lydia W: Population attributable risk (PAR) of overweight and obesity on chronic disease:south Australian representative, cross-sectional data, 2004-2006. Obes Res and Clin Pract 2009, 3:159-168.

34. Will RR, Janet BM: Epidemiology of obesity and chronic kidney disease. Adv Chronic Kidney Dis 2006, 13:403-417.

35. Zuzanna P, Federico PC, Wim V: Association of overweight and obesity with interest in healthy eating, subjective health and perceived risk of chronic diseases in three European countries. Appetite 2009, 3:399-406.

36. Bloomstein LZ, Gielchinsky I, Bernstein AD, Parsonnet B, Saunders C, Karanam T: Aortic valve replacement in geriatric patients: determinants of in-hospital mortality. Ann Thorac Surg 2001, 71:597-600.

\section{doi:10.1186/1749-8090-8-174}

Cite this article as: Wang et al: Obesity and the risk of late mortality after aortic valve replacement with small prosthesis. Journal of Cardiothoracic Surgery 2013 8:174. 